\title{
Incisional Hernia Repair: Laparoscopic or Open? A Randomized Clinical Trial
}

\author{
Omer Erturk $^{\mathrm{a}}$, Enver Ilhan ${ }^{\mathrm{a}}$, Fevzi Cengiz ${ }^{\mathrm{a}, \mathrm{b}}$, Savas Yakan , \\ Haci Osman Tanriverdi ${ }^{a}$
}

\begin{abstract}
Background: Incisional hernia that may occur following abdominal surgeries affect the quality of life and lead to loss of labor by causing morbidity. It is a continuing problem of surgery due to high rates of prevalence and morbidity. This study aimed to compare laparoscopic versus conventional method of incisional hernia repair.
\end{abstract}

Methods: Forty patients with incisional hernia who underwent hernia repair by laparoscopic $(n=20)$ or conventional $(n=20)$ technique between January 2010 and January 2011 in our clinic were included in the study. Preoperative, peroperative and postoperative data were collected prospectively, and the patients were followed up for a period of 1 year.

Results: No statistical difference was found between two hernia repair groups in terms of age, sex, number of previous abdominal surgery, distribution of incisional hernia and size of the defect. Mean body mass index $(\mathrm{BMI})$ was significantly $(\mathrm{P}=0.001)$ greater in laparoscopic group. No statistical difference was found between two groups in terms of duration of operation, while laparoscopic repair group was significantly advantageous over conventional repair group with regard to pain and discharge time. Complication rates were $15 \%$ and $40 \%$ in laparoscopic and conventional repair group, respectively. Only one recurrence occurred in either group within 1 year follow-up period.

Conclusions: Technological advances in laparoscopic surgery lead to shorter duration of operation, less pain and more rapid discharge from the hospital. It is concluded that lower rate of complication and applicability to obese patients render laparoscopic incisional hernia repair a more reliable and satisfactory technique compared with the conventional technique.

Manuscript accepted for publication April 15, 2013

${ }^{\mathrm{a}}$ Izmir Bozyaka Educational and Research Hospital, General Surgery Clinic, Turkey

${ }^{\mathrm{b}}$ Corresponding author: Fevzi Cengiz, Department of Surgery, Izmir Bozyaka Educational and Research Hospital, Izmir, 35140, Turkey. Email:drfevzi@gmail.com

doi: http://dx.doi.org/10.4021/jcs154w
Keywords: Incisional hernia; Laparoscopy; Laparoscopic incisional hernia; Mesh

\section{Introduction}

Incisional hernia is one of the most common complications of surgical interventions which affect the quality of life and lead to loss of labor by causing significant morbidity. Despite great care, incisional hernias occur in $10-25 \%$ of patients undergoing abdominal surgery [1]. Surgery is the only treatment of incisional hernia which is a continuing problem of surgery due to high rates of prevalence and morbidity. A broad range of surgical treatment is available from primary repair to repair with various prosthetic materials. Use of prosthetic materials is the principal choice in cases with inadequate intact tissue or large-sized defect. Although recurrence rate was reported as $50 \%$ in previous studies, it has been reduced to approximately $10 \%$ by use of prosthetic meshes recently [2].

Laparoscopic techniques, which have been increasingly used in surgery, have been used as alternative methods for incisional hernia repair following 1990s [3]. This technique has been proved reliable and applicable due to outcomes indicating reduced postoperative morbidity, duration of hospitalization and rate of recurrence compared with the conventional technique [4-8]. However, uncertainty continues on the laparoscopic technique of incisional hernia repair due to few numbers of prospective randomized studies with little number of cases, use of different techniques and short duration of follow-up [5-8].

The present study compared laparoscopic technique of incisional hernia repair versus the conventional method prospectively.

\section{Materials and Methods}

Forty patients with incisional hernia diagnosis who were internalized to our clinic between January 2010 and January 2011 were included in the study. Patients were randomized 
Table 1. Patient Demographics

\begin{tabular}{lccc}
\hline & Laparoscopic & Conventional & P \\
\hline Sex (F/M) & $13 / 7$ & $14 / 6$ & $0.736^{\mathrm{a}}$ \\
Mean age (Years) & $57 \pm 8.06$ & $59.75 \pm 9.87$ & $0.341^{\mathrm{b}}$ \\
Mean BMI & $29.82 \pm 5.6$ & $25.37 \pm 2.06$ & $0.001^{\mathrm{c}}$ \\
$\begin{array}{l}\text { Mean number of previous } \\
\text { abdominal surgery }\end{array}$ & $1.25 \pm 0.55$ & $1.60 \pm 1.14$ & $0.523^{\mathrm{c}}$ \\
Mean ASA & $1.75 \pm 0.55$ & & $0.046^{\mathrm{c}}$ \\
\hline
\end{tabular}

aPearson chi-square, 'Independent t test, cMann whitney u test.

into laparoscopic $(n=20)$ and conventional $(n=20)$ surgery groups and preoperative, peroperative and postoperative data were collected prospectively.

Patients who underwent urgent surgery and those with hernia defect size $<3 \mathrm{~cm}$ were excluded. Age, sex, body mass index (BMI) and American Society of Anesthesiologists (ASA) risk score were recorded before the surgery.

In addition number of previous abdominal operation, recurrence, localization of fascia defect during operation, size of the defect, size of prosthetic mesh used, duration of operation, pain evaluation using postoperative visual analogue scale (VAS) at $24 \mathrm{~h}$ [9] and discharge time were recorded.

Polypropylene mesh and Sepramesh IP Composite (Davol Inc., Warwick, RI) were used for hernia repair in conventional and laparoscopic repair group, respectively. Sizes of the hernia defects in all patients in both groups were measured on admission by physical exam and, in some cases, an additional measurement was made by the help of imaging methods.

Prophylaxis against bacterial infection and venous thromboembolism was made in all patients by one dose of Cephazolin sodium ( $1 \mathrm{~g}$ ) and low molecular-weight heparin (fraxiparine $0.4 \mathrm{MI} \mathrm{sc}$ ), respectively, $1 \mathrm{~h}$ before anesthesia induction. All patients received a non-steroidal anti-inflammatory agent (diclofenac sodium, $75 \mathrm{mg}$ iv, two times a day) in the postoperative period which was followed by oral analgesic.

Conventional technique utilized incisions on hernia defect along with abdominal onlay mesh application. Intact fascia edges were detached for $5 \mathrm{~cm}$ and prolene mesh was first sutured primarily using number 1 vicryl suture and then fixed continuously to the fascia by $2 / 0$ prolene suture. On the other hand, laparoscopic technique utilized intraperitoneal mesh application through use of a mesh size that exceeds

Table 2. Distribution of Incisional Abdominal Wall Hernias Localization by the European Hernia Society Classification

\section{Laparoscopic Conventional}

\begin{tabular}{llll}
\hline Midline & Epigastric M2 & 13 & 9 \\
& Umbilical M3 & 4 & 4 \\
Lateral & Subcostal L1 & 1 & 3 \\
& Flank L2 & 1 & 1 \\
& Iliac L3 & 1 & 3 \\
P-value & $\mathrm{P}=0.183^{\mathrm{c}}$ & $1.65 \pm 1.14$ & $2.35 \pm 1.57$
\end{tabular}

cMann whitney u test. 
Table 3. Surgical Technique, Short- and Long-Term Results

\begin{tabular}{lccc}
\hline & Laparoscopic & Conventional & P \\
\hline Mean defect diameter $(\mathrm{cm})$ & $5.6 \pm 2.84$ & $6.43 \pm 2.4$ & $0.242^{\mathrm{c}}$ \\
Mean mesh size $\left(\mathrm{cm}^{2}\right)$ & $124.49 \pm 100$ & $114.45 \pm 70.66$ & $0.820^{\mathrm{c}}$ \\
Mean operational duration (min) & $101 \pm 57.34$ & $106.5 \pm 24.93$ & $0.696^{\mathrm{b}}$ \\
Mean VAS score & $3.1 \pm 1.54$ & $4.5 \pm 2$ & $0.018^{\mathrm{b}}$ \\
Mean postoperative discharge duration (days) & $2.70 \pm 1.59$ & $3.60 \pm 1.50$ & $0.026^{\mathrm{c}}$ \\
Recurrence & 1 & 1 & $1^{\mathrm{a}}$ \\
\hline
\end{tabular}

${ }^{a}$ Pearson chi-square, ' Independent t test, 'Mann whitney u test.

3 - $4 \mathrm{~cm}$ on each side of the fascia defect which was determined by marking the abdominal skin. Besides classical laparoscopic tools, Spiral Tacker (Origin Medical Systems, Menlo Park, California) and transfixion suture tools for intraperitoneal fixation of the greft were used. Abdominal wall posterior adhesions were cleared and a laparoscopic seal was used in order to avoid bowel injury and to maintain hemostasis. Suture Passer was also used along with Spiral Tacker in order to take out the vicryl suture ends that were already attached to the mesh providing fixation of the graft to the abdominal wall. Spiral tacker was used each with $2 \mathrm{~cm}$ distance following placement of vicryl sutures at a distance of $3-4$ $\mathrm{cm}$ from fascia defect and fixation on mesh edge, while open fascia edges were not closed primarily.
Insufflation was performed through the first trocar (10 $\mathrm{mm}$ long) which was placed away from the defect according to open Hasson technique. Abdomen was explored following insertion of the laparoscope. The other two trocars (each 5 $\mathrm{mm}$ long) were placed under dirct vision between anterior and mid-axillary lines with a greatest distance of $5 \mathrm{~cm}$.

Data were analyzed using SPSS software version 19. Pairwise comparisons were made using the parametric independent $t$ test and the non-parametric Mann Whitney- $U$ test. Relation between variables was made using Kendall's Tau-b, while chi square test and one sample Kolmogorov Smirnov test (uniform) were used. Results were calculated within $95 \%$ confidence interval with a maximum margin of error of $0.05 \%$. A P value $<0.05$ was considered statistically

Table 4. Distribution of Complications Among Groups by the Clavien Classification

\begin{tabular}{lll} 
Clavien-Dindo classification & N. of Laparoscopic cases & N. of Conventional cases \\
\hline No complication & 17 & 12 \\
Grade I & 3 & 7 \\
Grade II & 0 & 0 \\
Grade III & 0 & 0 \\
Grade IV & 0 & 0 \\
Grade V & 0 &
\end{tabular}

aPearson chi-square. 
significant.

\section{Results}

Table 1 summarizes demographic features and statistical comparisons of surgery groups. No statistical difference was found between the two groups in terms of age and gender. Laparoscopic repair group, which contained 6 patients with BMI values higher than 30 , had significantly greater mean BMI value compared with that in conventional repair group (Table 1).

Ten patients, of whom $4(10 \%)$ were in laparoscopic repair group and $6(15 \%)$ were in conventional repair group, had a history of more than one previous abdominal surgery. However, no statistical difference was found between two groups in terms of number of previous abdominal surgery and localization of incisional hernia (Table 1,2). ASA score, which evaluates preoperative risk with regard to anesthesia, was significantly greater in patients in conventional repair group (Table 1).

No statistical difference was found between groups in terms of mean defect size, mean diameter of mesh used and duration of operation. Mean VAS values evaluated 24 $\mathrm{h}$ postoperatively, as well as time until discharge were significantly lower in laparoscopic repair group compared with conventional repair group (Table 3 ).

Complications were observed in a total of $11(27.5 \%)$ cases, $3(15 \%)$ in laparoscopic and $8(40 \%)$ in conventional group, in our study. Except for a pulmonary complication in 1 patient in the conventional group, all complications were classified as Grade I according to Clavien classification and no significant difference was detected between groups $(\mathrm{P}=$ 0.07) (Table 4).

In addition, long-term complications were observed in $2(5 \%)$ patients ( 1 in each group) during one-year follow-up period.

\section{Discussion}

Incisional hernia is a significant problem both surgically and socio-economically. Although the use of prosthetic materials reduced recurrence rates as opposed to primary repair, surgical challenges are consistently faced. Laparoscopic hernia repair has become popular due to development of minimal invasive surgical techniques. Principal benefits of laparoscopic surgery include decreased wound infection risk, less pain and reduced requirement to analgesics, accelerated recovery and rapid return to labor. Although age, sex, incisional hernia localization and mean defect size were comparable in two surgery groups, BMI was significantly greater in laparoscopic repair group with $>30$ in 6 patients in this group. Kurman et al [10] reported that a BMI value greater than 30 is a predisposing factor for recurrence regardless of the surgical technique used, however, no significant difference was observed in our study between surgery groups in terms of recurrence.

Park et al reported cardiopulmonary complication rates of $1.7 \%$ and $10.2 \%$ in patients who underwent laparoscopic and conventional hernia repair, respectively [5]. We did not observe a cardiopulmonary complication in laparoscopic repair group while postoperative atelectasis was detected in 1 $(2.5 \%)$ patient in conventional repair group. This patient was discharged following medical treatment. We suggest that the difference between two surgery groups in terms of cardiopulmonary complication could be due to preoperative ASA score which was significantly greater in conventional repair group.

Although longer or similar duration of operation with laparoscopic technique compared to the conventional method was reported by different studies $[5,6,11,12]$, recent literature supports shorter operational duration with laparoscopic technique due to technological advancements [13, $14,15]$. Carbajo et al reported that operational duration was reduced by $50 \%$ by the help of external knotting technique which was also used in our laparoscopic surgery [16], however, duration of operation in laparoscopic repair group was not significantly decreased compared with the conventional technique in our study. Mean operational duration was 101 min (range 45 - $300 \mathrm{~min}$ ) and $106.5 \mathrm{~min}$ (range 60 - $150 \mathrm{~min}$ ) in laparoscopic and conventional repair group, respectively. Although operational duration was the longest (300 $\mathrm{min})$ in our first case of incisional hernia repair with laparoscopic technique, it was shortened gradually with increasing number of patients who underwent laparoscopic incisional hernia repair.

Rate of complication is lower in laparoscopic technique compared with the conventional method $[5,6,9,15]$. A previous study reported $58 \%$ less complication rate in patients who underwent laparoscopic hernia repair compared with the conventional technique [12]. One of the most common complications in hernia repair with laparoscopic mesh is seroma which occurs due to broad dissections or dead volumes and generally shows spontaneous regression requiring no intervention. We did not observe seroma in the laparoscopic repair group in our study. Although Carbajo et al reported 4 cases with seroma in a 30-patient series [16] and Park et al reported 2 cases with seroma in a 56-patient series [5], in agreement with our study, Reitter et al reported no case with seroma in a 49-patient series [17]. Interestingly, a number of studies reported higher rate of seroma in patients who underwent laparoscopic repair than those who underwent conventional hernia repair $[14,18]$. We suggest that use of sepramesh in our study prevented dead volume, and, hence, seroma occurrence [19]. We detected 3 cases $(7.5 \%)$ with seroma in conventional repair group; seroma was drained surgically in one case while it regressed spontaneously in 
2 cases.

Postoperative hematoma was reported in 3, 2 and 1 patient in studies of Heniford et al with 407 patients [4], Toy et al with 144 patients [20] and Carbajo et al with 30 patients [16]. Taker and suture passer need to be applied with great care during mesh fixation after determining vessel traces particularly to avoid epigastric vessel injury. We did not observe postoperative hematoma in patients who underwent laparoscopic hernia repair by the use of laparoscopic vascular sealing device.

Mesh infection is a significant problem in laparoscopic or conventional hernia repair. In contrast to septic onlay mesh that could be managed by simple open wound care, the mesh must be removed in laparoscopic group in the case of an infection hernia repair is delayed for at least 6 months. Infections occur due to broad dissection for graft placement, wide skin incisions over prosthetic material and use of external drainage systems. Rate of wound infection requiring mesh removal is extremely low [21]. Skin pathogens are generally responsible from such infections. Rate of wound complications and infection are reported to vary between $12-20 \%$ in hernia repair with prosthetic material [7] and increased complication parallels increased recurrence $[2,5$, $15,22,23]$. Large-scale studies conducted by experienced centers reported that rate of wound infection by laparoscopic hernia repair was $1.3-10.4 \%$ [21]. In our study, we observed no wound infection in patients who received laparoscopic hernia repair and in $1(2.5 \%)$ patient who underwent conventional repair. The wound infection in this patient was managed by local wound care and antibiotic therapy.

Rate of intestinal injury in laparoscopic hernia repair was reported as $3.5 \%$ in the literature [15]. We did not observe intestinal injury in either group in our study. Sharp dissection was performed and operation table was moved for better anatomic view in laparoscopic hernia repair group in order to avoid intestinal injury.

Postoperative prolonged ileus is one of the most common complications in both type of hernia repair [4, 5]. Postoperative prolonged ileus was detected in a total of 5 $(12.5 \%)$ cases probably due to large incisional hernia defect which resulted in broad dissection and prolonged operational duration. These patients recovered following conservative therapy.

Duration of hospital stay is reportedly shorter in laparoscopic hernia repair compared with the conventional technique $[15,21,24,25]$. Mean hospital stay was reported as 2 days, 2.3 days and 2.7 days in the series of Carbajo et al [16], Heniford et al [4] and Lomanto et al [26], respectively. We found in our study that means duration of hospital stay (2.7 days) was significantly lower in laparoscopic repair group compared with the conventional repair group (3.6 days). The longer duration of hospital stay in conventional repair group might be due to greater postoperative pain score (VAS) and delayed mobilization in these patients.
Patients may suffer from pain or local sensitivity at transabdominal fixation areas following laparoscopic hernia repair. Postoperative pain on the suture site is due to squeezed nerves within the transfixation sutures. This complication is rare with resorbable sutures [27]. The pain can last longer than 6 weeks in some cases; these patients can be managed by non-steroidal anti-inflammatory drugs and narcotic analgesics, as well as subfascial local anesthetics [28].

Recurrence constitutes one of the most important problems in incisional hernia repair; $90 \%$ of all recurrences appear in the first 3 years after the surgery [2]. Recurrence rate is increased by morbid obesity, unsuccessful operations, large defects and postoperative complications [7]. Recurrence rates in conventional and laparoscopic hernia repairs are still ambiguous. A randomized controlled study reported a rate of $34 \%$ recurrence with conventional incisional hernia repair with mesh [29]. Rate of recurrence in Stoppa's repair using mesh larger than the defect was $2 \%$ [30] and recurrence rate after open repair was reported as $3.6 \%$ in a review by Heniford and colleagues [4]. In addition, a metaanalysis reviewing laparoscopic series reported a recurrence rate of $3.4 \%$ and found no statistical difference with recurrence rate reported for the open technique [21]. We observed recurrences in a total of $2(5 \%)$ patients, one patient in each group, after a 1-year follow-up period. Both patients were operated due to recurrent incisional hernia. New studies with larger population and longer duration are required to exactly determine the rates of recurrence in laparoscopic versus conventional hernia repair.

In conclusion, the laparoscopic technique reduces operational duration, postoperative pain, mobilization time and duration of hospital stay in hernia repair. Other advantages of laparoscopic method include applicability in obese patients, better outcomes, and lower risk of seroma occurrence and wound infection. On the other hand, higher operational cost seems to be a disadvantage of laparoscopic hernia repair. We believe that laparoscopic technique is a reliable and satisfactory alternative to the conventional technique in terms of hernia repair. Nevertheless, observation of larger populations for longer durations is required to evaluate the rate of recurrence in both techniques.

\section{References}

1. Muller-Riemenschneider F, Roll S, Friedrich M, Zieren J, Reinhold T, von der Schulenburg JM, Greiner W, et al. Medical effectiveness and safety of conventional compared to laparoscopic incisional hernia repair: a systematic review. Surg Endosc. 2007;21(12):2127-2136.

2. Wolter A, Rudroff C, Sauerland S, Heiss MM. Laparoscopic incisional hernia repair: evaluation of effectiveness and experiences. Hernia. 2009;13(5):469-474. 
3. Flum DR, Horvath K, Koepsell T. Have outcomes of incisional hernia repair improved with time? A population-based analysis. Ann Surg. 2003;237(1):129-135.

4. Heniford BT, Park A, Ramshaw BJ, Voeller G. Laparoscopic ventral and incisional hernia repair in 407 patients. J Am Coll Surg. 2000;190(6):645-650.

5. Park A, Birch DW, Lovrics P. Laparoscopic and open incisional hernia repair: a comparison study. Surgery. 1998;124(4):816-821; discussion 821-812.

6. Holzman MD, Purut CM, Reintgen K, Eubanks S, Pappas TN. Laparoscopic ventral and incisional hernioplasty. Surg Endosc. 1997;11(1):32-35.

7. Heniford BT, Park A, Ramshaw BJ, Voeller G. Laparoscopic repair of ventral hernias: nine years' experience with 850 consecutive hernias. Ann Surg. 2003;238(3):391-399; discussion 399-400.

8. Parker HH, 3rd, Nottingham JM, Bynoe RP, Yost MJ. Laparoscopic repair of large incisional hernias. Am Surg. 2002;68(6):530-533; discussion 533-534.

9. Wewers ME, Lowe NK. A critical review of visual analogue scales in the measurement of clinical phenomena. Res Nurs Health. 1990;13(4):227-236.

10. Kurmann A, Visth E, Candinas D, Beldi G. Long-term follow-up of open and laparoscopic repair of large incisional hernias. World J Surg. 2011;35(2):297-301.

11. Ramshaw BJ, Esartia P, Schwab J, Mason EM, Wilson RA, Duncan TD, Miller J, et al. Comparison of laparoscopic and open ventral herniorrhaphy. Am Surg. 1999;65(9):827-831; discussion 831-822.

12. Goodney PP, Birkmeyer CM, Birkmeyer JD. Short-term outcomes of laparoscopic and open ventral hernia repair: a meta-analysis. Arch Surg. 2002;137(10):1161-1165.

13. Navarra G, Musolino C, De Marco ML, Bartolotta M, Barbera A, Centorrino T. Retromuscular sutured incisional hernia repair: a randomized controlled trial to compare open and laparoscopic approach. Surg Laparosc Endosc Percutan Tech. 2007;17(2):86-90.

14. Olmi S, Scaini A, Cesana GC, Erba L, Croce E. Laparoscopic versus open incisional hernia repair: an open randomized controlled study. Surg Endosc. 2007;21(4):555559.

15. Forbes SS, Eskicioglu C, McLeod RS, Okrainec A. Meta-analysis of randomized controlled trials comparing open and laparoscopic ventral and incisional hernia repair with mesh. Br J Surg. 2009;96(8):851-858.

16. Carbajo MA, Martin del Olmo JC, Blanco JI, de la Cuesta C, Toledano M, Martin F, Vaquero C, et al. Laparoscopic treatment vs open surgery in the solution of major incisional and abdominal wall hernias with mesh. Surg Endosc. 1999;13(3):250-252.

17. Reitter DR, Paulsen JK, Debord JR, Estes NC. Five-year experience with the "four-before" laparoscopic ventral hernia repair. Am Surg. 2000;66(5):465-468; discussion 468-469.

18. Barbaros U, Asoglu O, Seven R, Erbil Y, Dinccag A, Deveci U, Ozarmagan S, et al. The comparison of laparoscopic and open ventral hernia repairs: a prospective randomized study. Hernia. 2007;11(1):51-56.

19. Kapischke M, Schulz T, Schipper T, Tensfeldt J, Caliebe A. Open versus laparoscopic incisional hernia repair: something different from a meta-analysis. Surg Endosc. 2008;22(10):2251-2260.

20. Toy FK, Bailey RW, Carey S, Chappuis CW, Gagner M, Josephs LG, Mangiante EC, et al. Prospective, multicenter study of laparoscopic ventral hernioplasty. Preliminary results. Surg Endosc. 1998;12(7):955-959.

21. Karthikesalingam A, Markar SR, Holt PJ, Praseedom RK. Meta-analysis of randomized controlled trials comparing laparoscopic with open mesh repair of recurrent inguinal hernia. Br J Surg. 2010;97(1):4-11.

22. Millikan KW. Incisional hernia repair. Surg Clin North Am. 2003;83(5):1223-1234.

23. van der Linden FT, van Vroonhoven TJ. Long-term results after surgical correction of incisional hernia. Neth J Surg. 1988;40(5):127-129.

24. Sains PS, Tilney HS, Purkayastha S, Darzi AW, Athanasiou T, Tekkis PP, Heriot AG. Outcomes following laparoscopic versus open repair of incisional hernia. World J Surg. 2006;30(11):2056-2064.

25. DeMaria EJ, Moss JM, Sugerman HJ. Laparoscopic intraperitoneal polytetrafluoroethylene (PTFE) prosthetic patch repair of ventral hernia. Prospective comparison to open prefascial polypropylene mesh repair. Surg Endosc. 2000;14(4):326-329.

26. Lomanto D, Iyer SG, Shabbir A, Cheah WK. Laparoscopic versus open ventral hernia mesh repair: a prospective study. Surg Endosc. 2006;20(7):1030-1035.

27. Martin-Duce A, Noguerales F, Villeta R, Hernandez P, Lozano O, Keller J, Granell J. Modifications to Rives technique for midline incisional hernia repair. Hernia. 2001;5(2):70-72.

28. Carbonell AM, Harold KL, Mahmutovic AJ, Hassan R, Matthews BD, Kercher KW, Sing RF, et al. Local injection for the treatment of suture site pain after laparoscopic ventral hernia repair. Am Surg. 2003;69(8):688691; discussion 691-682.

29. Luijendijk RW, Hop WC, van den Tol MP, de Lange DC, Braaksma MM, JN IJ, Boelhouwer RU, et al. A comparison of suture repair with mesh repair for incisional hernia. N Engl J Med. 2000;343(6):392-398.

30. Stoppa RE. The treatment of complicated groin and incisional hernias. World J Surg. 1989;13(5):545-554. 